Special issue of the 3rd International Conference on Computational and Experimental Science and Engineering (ICCESEN 2016)

\title{
Residual Stresses Measurement in the Weld Seam of X70 Steel, Analyzed by XRD
}

\author{
M. Hamdi ${ }^{a, *}$, H.A. Benhorma ${ }^{a}$, A. Hadjaj ${ }^{b}$ And A. Benchatti ${ }^{c}$ \\ ${ }^{a}$ University of Amar Thelidji, Department of Genie Mechanic, Laghouat, Algeria \\ ${ }^{b}$ University of Amar Thelidji, Laboratory LACOSER of Genie Electric, Laghouat, Algeria \\ ${ }^{c}$ University of Amar Thelidji, Laboratory of Genie Mechanic, Laghouat, Algeria
}

\begin{abstract}
Determination of residual stresses in the welded areas of metal structures is a very important operation in the mechanical construction and other fields, for the reliability and sustainability of these metal structures [J.B. Ju, S.K. Lee, J. Jang, W.S. Kim, D. Kwon, Int. J. Press. Vessels Piping 80, 641 (2003)]. Over the past few years, a significant number of studies have been carried out in order to understand the influence of residual stresses on the assembly by welding, from the standpoint of mechanical properties and corrosion resistance [E. Macherauch, K.H. Kloos, Residual Stresses in Science and Technology, DGM Inform. Verlag, 1987, p. 3; P.J. Withers, H.K.D.H. Bhadeshia, Master Sci. Technol. 17, 366 (2001)]. Several studies have been carried out for the purpose of finding non-destructive methods for the evaluation of the residual stress [H. Nasri, Mesure De Contraintes Résiduelles Dues Au Soudage Et Au Soudage-Martelage Par Micro-Profil De Surface, Ecole De Technologie Supérieure Université Du Québec, 2007; C. Balasingh, A.K. Singh, Metals Materials Proc. 12, 269 (2000)]. One of the methods that proved important, it is that of $\sin \psi^{2}$. In this work we have applied this method in the assessment of the residual stress in the welded X70 steel.
\end{abstract}

DOI: $10.12693 /$ APhysPolA.132.866

PACS/topics: welding, residual-stresses, HAZ, steel-X70, $\sin \psi^{2}$-method

\section{Introduction}

In this study, the residual stress in the welded X70 steel plates was measured by XRD scanning based on $\sin \psi^{2}$ method, which was developed for the measurement of residual stresses (RS) in small welded or plastically deformed zones. This method takes into account the crystallographic orientations, the geometry of the measurement (the angle of incidence and angles of inclination) in order to know the depth of weld penetration and heat affected zone (HAZ). Each generated constraints mechanism has its own effects on the distribution of these residual stresses, and, depending on the system, shifts the dislocations in the most favorable crystallographic planes $[1,2]$.

\section{Welding residual stresses}

The residual stresses, due to substantial thermal shifts, cause micro deformations and thermo-mechanical concentration unbalance, at significant variations of temperature. These stresses, also known as thermal stresses, disappear after applying a softening heat treatment, due to the shear effect on the lines of dislocations, which disappear by cancellation in the joints of the grains or by the migration of these dislocations to the surface of the material [3].

When the cooling speed is high, plastic deformation occurs. During the process of welding, the welded area

*corresponding author; e-mail: asmosoft@gmail.com is greatly heated, compared to the peripheral zone, and then merged locally; the material expands accordingly. The thermal expansion affects the surrounding area, which is colder, giving rise to thermo-mechanical and plastoelastic stresses, due to the expansion and friction of lattice and due to phase transformations. Therefore, a high concentration of residual stress in different grains of the material is formed.

\section{Residual stresses measurement techniques}

The $\sin \psi^{2}$ method of measurement of the residual stress in crystalline materials has been developed using the value $\Delta \theta$ (diffraction difference, in comparison to the theoretical value of the Bragg's law)

$$
n \lambda=2 d \sin \theta,
$$

where $n$ is diffraction order (an integer number), $\theta$ is the diffraction angle, $d$ is the interplanar spacing of the family of the diffracted planes and $\lambda$ is the wavelength.

$$
\varepsilon=\frac{\Delta d}{d}=\cot \theta_{d} \Delta \theta
$$

where $\varepsilon$ is the deformation rate, $\theta_{d}$ is the diffraction angle without the internal stresses. The applied stress $\sigma$ is then calculated from the following expression

$$
\begin{aligned}
\sigma & =\frac{E}{1+\nu} \frac{\partial(\varepsilon)}{\partial\left(\sin ^{2} \psi\right)}= \\
& -\frac{E \cot \theta_{d}}{2(1+\nu)} \frac{\partial(\theta)}{\partial\left(\sin ^{2} \psi\right)}=K M,
\end{aligned}
$$

where $\psi$ is the angle between the normal at the sample surface and that of the diffracting planes. The above equation may be expressed as a product of the constant 
$K$ (elastic constant for measuring stresses by X-rays) and $M$, the gradient of the regression line of the data, representing the results of the stresses for the different values of angle $\psi$. It can be calculated from three and more points, the coordinates of which are $\left(2 \theta \psi x, \sin \psi^{2}\right)$, by using Eq. (3). There is a linear relationship between $2 \theta$ and $\sin \psi^{2}[4]$.

\section{Experimental study}

The studied material is the steel X70 of the norm API 5L. Its chemical composition is presented in Table I. The welded zone is shown in Fig. 1. The dimensions of the samples were $100 \times 40 \times 5.7 \mathrm{~mm}^{3}$.

TABLE I

Chemical composition of the steel X70 (weight \%, max).

\begin{tabular}{c|c|c|c|c|c|c|c|c}
\hline \hline $\mathrm{C}$ & $\mathrm{Si}$ & $\mathrm{Mn}$ & $\mathrm{Ni}$ & $\mathrm{Al}$ & $\mathrm{Cu}$ & $\mathrm{Cr}$ & $\mathrm{Ti}$ & $\mathrm{Nb}$ \\
\hline 0.04 & 0.39 & 1.48 & 0.08 & 0.31 & 0.16 & 0.03 & 0.02 & 0.05
\end{tabular}

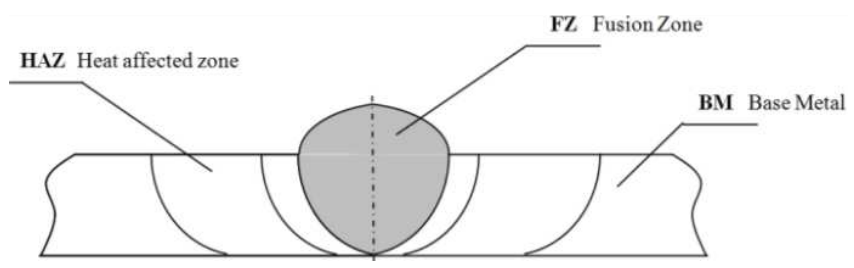

Fig. 1. Scheme of the weld seam.

The measurement of stresses by X-ray was performed by the fixed process (method $\psi, \psi$-diffractometer). The size of the beam of X-rays was of the order of $4 \times 4 \mathrm{~mm}^{2}$, taking into account the size of coarse grains in the welded area. The employed Philips diffractometer is composed of a monochromatic X-ray source, a sample holder and a detector of x-rays. The latter records the intensity of the diffracted light, based on the angle of diffraction. The acquired data is saved in a computer and then analyzed in accordance with the database.

The X-rays are emitted from a cathode $\mathrm{Cu} \mathrm{K}_{\alpha}=$ $1.54 \AA$. The parameters of the process for all samples are $40 \mathrm{kV}$ and $50 \mathrm{~mA}$ with a step size of 0.020 and a counting time per step of one second. The angle of orientation of the sample and the normal to the surface of sample was changed between $0^{\circ}, 45^{\circ}$ and $90^{\circ}$, in the experiments. Diffraction peak (211) for X70 steel, for $\mathrm{Cu} \mathrm{K}$, is located at $2 \theta=156^{\circ}$.

The values of residual stresses of the welding zone have been obtained by analysis and calculation, using the method of $\sin \psi^{2}$ and a Visual Basic program.

\section{Results and analysis}

The measured stresses are given in Fig. 2, which shows the value of the maximum stress of approximately $615 \mathrm{MPa}$ in $\mathrm{FZ}$. The stresses in BM are relatively low, of the order of $21.25 \mathrm{MPa}$, whereas in the HAZ, the value is approximately $200 \mathrm{MPa}$.

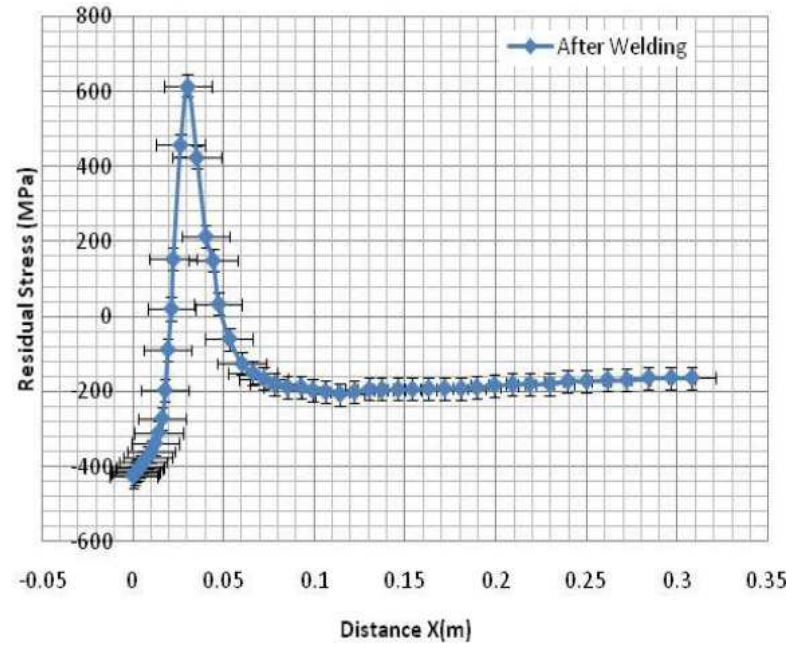

Fig. 2. Residual stresses after welding.

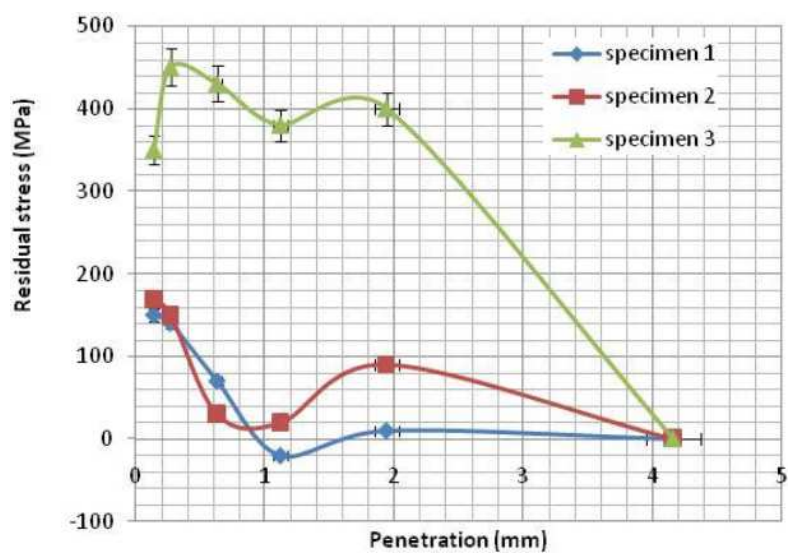

Fig. 3. Longitudinal residual stresses after welding.

The values of longitudinal residual stresses obtained in the base metal (specimen 1) are given in Fig. 3. The decrease of stresses, away from the weld seam, can be explained by the grains growth, due to the effect of coalescence, which causes the reduction of surfaces of the grains joints, which subsequently minimizes the internal stresses. In the HAZ (specimen 2), the values of residual stresses decrease to value of $180 \mathrm{MPa}$, depending on the proximity of the regions in the FZ (specimen 3 ). Figure 3 shows the variation of residual stress up to $460 \mathrm{MPa}$, at $0.3 \mathrm{~mm}$, along the normal to the surface, calculated using the $\sin \psi^{2}$ method, in three zones (FZ, BM and HAZ). Thus, we can say that in the area of BM the evolution of residual stresses is not well marked because the area of $\mathrm{BM}$ is not thermally deformed.

\section{Conclusions}

The profiles of residual stresses in welded X70-API5L plates were determined using $\sin \psi^{2}$ method, by measurement of the X-ray diffraction. In conclusion, both the 
X-ray diffraction method and the application of the $\sin \psi^{2}$ method have proved to be reliable in assessing the rates of residual stress in the depth of the weld, as well as the remains of the adjacent areas. On the basis of analysis we underline, that the residual stress is concentrated in the fusion zone, which is a mechanically vulnerable site, due to the spread of micro-cracks that develop into the macro cracks.

\section{References}

[1] A. Castrataro, Ms. Sc. Thesis, Université Du Québec, 2006 .
[2] C.H. Gür, Prediction of surface residual stresses in butt-welded steel plates by magnetic barkhausen noise analysis, in: 10th European Conference on NDT, Moscow 2010.

[3] J. Peng, Ph.D. Thesis, ENSAM, Paris 2006.

[4] R. Ahmed, M. Hadfield, Wear 209, 84 (1997). 